\title{
Tide and surge dynamics along the Iberian Atlantic coast
}

\author{
Enrique ALVAREZ FANJUL*, Begoña PEREZ GOMEZ, Juan Carlos CARRETERo, Ignacio RodRÍGUEZ \\ SANCHEZ AREVALO
}

Clima Marítimo, Puertos del estado, Antonio Lopez 81, 28026, Madrid, Spain

(Revised 05/01/98, accepted 08/01/98)

\begin{abstract}
The eastern Atlantic harotropic dynamics (in a region spanning from $20^{\circ} \mathrm{N}$ to $48^{\circ} \mathrm{N}$ and $34^{\circ} \mathrm{W}$ to $0^{\circ}$ ) are studied through numerical modelling and in situ measurements. The main source of data is the tidal gauge network REDMAR, managed by Clima Marítimo (Puertos del Estado). The numerical model employed is the HAMSOM, developed both by the Institut für Meereskunde (Hamburg University) and Clima Marítimo.

In this paper, tidal and storm surge dynamics are studied for the region, focusing particularly on the nonlinear transfer of energy between the different forcings.

The results of tidal simulations show good agreement between semidiurnal harmonic components and the values obtained from the tidal gauges (both coastal and pelagic) and current metres. The nonlinear transfers of energy from semidiurnal to higher order harmonics, such as M4 and M6, were mapped. Those transfers were found to be important in only two areas: The French continental shelf in the Bay of Biscay and the widest part of the African shelf, south of Cabo Bojador. The modelled diurnal constituents show larger relative differences with measurements than semidiurnal harmonics, especially in data concerning the phase.

A method to isolate the nonlinear transfers of energy between tidal and atmospheric forcing during a storm surge was developed. These transfers were found to be significant in the same areas where tidal nonlinear activity was present.

The effect of short period wind generated waves on sea surface elevation was also investigated. The magnitude of the spatial derivatives of radiation stress was compared with wind-induced stress. As a result of this comparison, we found the inclusion of a forcing term that depends on radiation stress in ocean model simulations at this scale and resolution to be not essential. The effect of computing wind-induced stresses, with a formulation that explicitly depends on sea state, was also explored by means of a coupled run of the HAMSOM and the spectral wave model WAM for a storm surge event in the Spanish coast. This formulation was not found to be an improvement over a classical parameterisation which only depends on wind fields. (C) Elsevier, Paris
\end{abstract}

\section{surge / tide / wave / model coupling / tide gauge network REDMAR}

Résumé - Dynamique de marée et d'onde de tempête en Atlantique devant la péninsule ibérique. La dynamique barotrope du nord-est de l'Atlantique $\left(20^{\circ} \mathrm{N}\right.$ à $48^{\circ} \mathrm{N}, 34^{\circ} \mathrm{W}$ à $\left.0^{\circ}\right)$ a été étudiée par modélisation numérique et mesures in situ. Les données proviennent du réseau des marégraphes REDMAR géré par Clima Maritimo (Puertos del Estado). Les simulations numériques ont été faites avec le modèle tridimensionnel HAMSOM développé par l'Institut für Meereskunde (université de Hambourg) et par Clima Marítimo. Dans le présent travail, une attention particulière est portée aux transferts non linéaires d'énergie entre les différents éléments de forçage.

Les résultats des simulations de marée montrent un bon accord entre les composantes harmoniques semi-diurnes et les valeurs obtenues par marégraphie (côtière et pélagique) et courantométrie. Le transfert non linéaire d'énergie a été calculé à partir des composantes harmoniques semi-diurnes et de composantes d'ordres supérieurs, comme M4 et M6. Ces transferts ne sont importants qu'en deux endroits : sur le plateau continental français du golfe de Gascogne et dans la partie la

* Correspondence and reprints 
plus large du plateau continental africain, au sud du cap Bojador. Contrairement aux composantes harmoniques semi-diurnes, les composantes diurnes modélisées s'écartent des mesures in situ, particulièrement en ce qui concerne les phases. Une méthode a été développée pour isoler les transferts non linéaires d'énergie entre forçages astronomique et atmosphérique lors d'une surélévation de tempête ; les transferts importants se produisent aux endroits où l'activité non linéaire de marée est forte.

L'élévation de la surface sous l'effet des vagues de courtes périodes engendrées par le vent est également étudiée. La comparaison de la dérivée spatiale du tenseur de radiation et de la tension tangentielle produite par le vent montre que, à l'échelle et à la résolution utilisées dans cette simulation océanique, on peut négliger le terme de forçage dépendant des tenseurs de radiation. Les tensions tangentielles produites par le vent on été simulées, en prenant en compte l'état de la mer dans un épisode de tempête sur la côte espagnole, par couplage entre le modèle HAMSOM et le modèle spectral WAM. Cette formulation n'apporte aucune amélioration aux résultats par rapport à l'approche classique où la tension ne dépend que du champ de vent. (C) Elsevier, Paris

\section{onde de marée / marée / vague / couplage / réseau de marégraphie REDMAR}

\section{INTRODUCTION}

The aim of the present paper is to study, through numerical methods and in situ measurements, the barotropic dynamics of the eastern Atlantic to get a better understanding of the different phenomena involved in the description of sea surface elevation and the interaction between them.

We will focus on barotropic dynamics because these processes govern the sea surface elevation variability at short time scales. In fact, operational numerical models developed to predict sea surface elevation are usually barotropic, vertically integrated and driven by tidal and meteorological forcing which includes wind-induced stresses and sea surface atmospheric pressure [25].

This paper is structured in two sections: first materials and methods and second results. Both sections are organised following the same logical steps that were applied during the work to obtain a global description of the barotropic processes: as a first step, tidal dynamics are prospected through numerical modelling and in situ measurements, placing special focus on nonlinear phenomena. In a second step, the same tools are applied to obtain a description of storm surge dynamics in the region. In this part we explore the effect of sea state on sea surface elevation during the storm. Finally, the nonlincar transfer of energy between tidal and metcorological forcings is investigated.

The field of tidal research [7] has experienced an important progress in the last decade due to the availability of satcllite altimeter data [16] and the continuous incrcase in computing power. Recent numerical solutions based on TOPEX-POSEIDON data show accurate solutions in global models. Comparison with data from a set of
78 pelagic and stations on islands show differences of about $6 \%$ for M2 [16]. In this paper we use one of these new data sets to feed a high resolution implementation of the HAMSOM ocean model in the eastern Atlantic to study the tidal dynamics and the interaction between tides and meteorological forcings.

In July 1992, the REDMAR (RED de MAReógrafos) tidal gauge network became operational [19]. The network is funded by the Spanish holding of harbours and the data produced are used for daily harbour management as well as for research purposes. We used the data obtained from this network to validate our numerical model and, at the same time, we used the simulations to extend the availability of the data to regions where no tidal gauges are present and to obtain a better understanding of the relative importance of the physical processes involved in the evolution of the sea surface elevation.

As mentioned earlier, sea surface evolution is strongly influenced by fluctuations of wind and atmospheric pressure. These forcings can produce, during storm events, deviations up to $50 \mathrm{~cm}$ from tidal-predicted sea surface elevations in the Spanish coasts. Evolution of sea surface elevation during a storm surge event is strongly influenced by bathymetry. In seas with a wide continental shelf, like the North Sea, surge evolution is dominated by the wind. The Iberian Peninsula presents a very narrow shelf (figure 1), bcing sca surface clevation residuals (the result of subtracting tidal harmonically predicted elevation to tidal gauges measurements) mostly produced by pressure variations. In fact, a first rough estimate of the residuals in the Spanish harbours can be ohtained throngh the study of the time series of inverted atmospheric pressure records.

The barotropic set of equations contains nonlinear terms. (see later description of the HAMSOM model equations). 


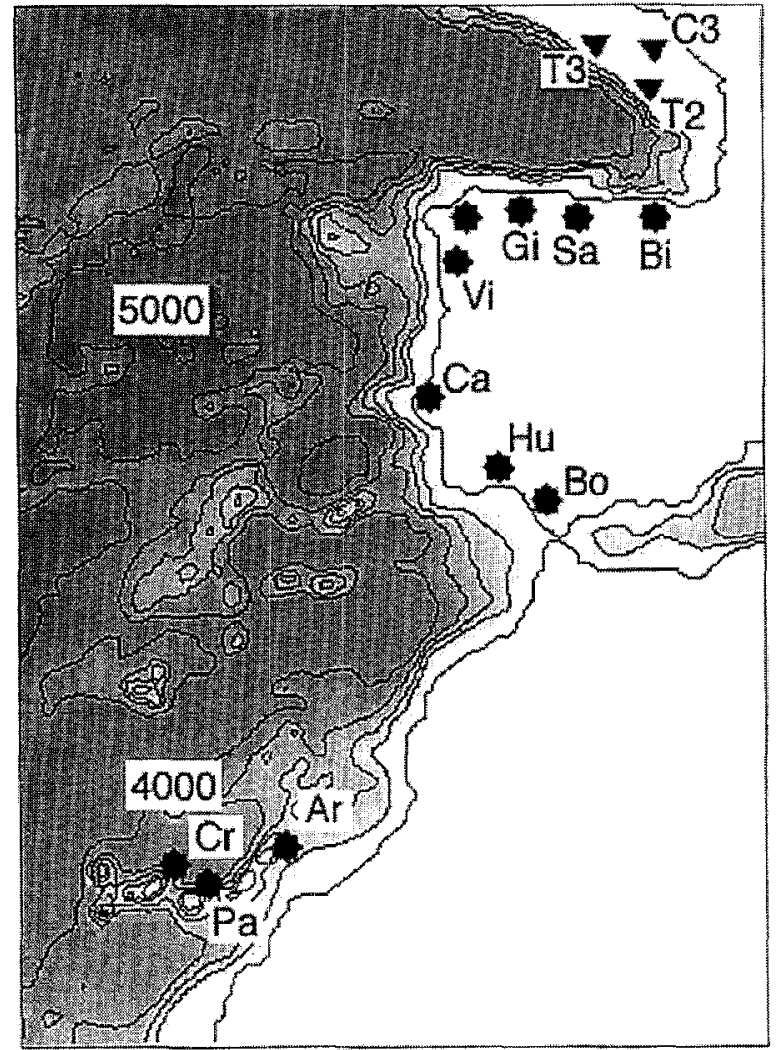

Figure 1. Bathymetry employed in the numerical simulations (contours in $\mathrm{m}$ ). The positions of the REDMAR tidal gauges employed in this work are marked with stars: Bilbao (Bi), Santander (Sa), Gijón (Gi), La Coruña (Co), Vigo (Vi), Huelva (Hu), Bonanza (Bo), Las Palmas (Pa) and Santa Cruz de Tenerife (Cr). Two additional stations were included for completeness: Cascais (Ca) and the Instituto Español de Oceanografía station at Arrecife (Ar). The inverted triangles show the location of current metres employed in the model validation.

One of the effects of these terms is to transfer energy contained in one frequency to another [6]. For example, M2 tidal constituent generates harmonics (M4, M6) with frequencies that are multiples of the original. In addition, the residual elevation during a storm surge is modified by nonlinear interactions with the tide. In very shallow seas these nonlinear contributions cannot be neglected, and, in fact, are critical to predict the evolution of sea surface. In the North Sea and the English Channel, for example, M4 becomes an important harmonic and residuals cannot be properly predicted without the contribution of energy from tides [20].

In order to obtain a better understanding of the physical processes involved in the evolution of sea surface eleva- tion and to provide storm surge modelling assessment for Spanish harbours, we selected and studied through numerical modelling and observations a typical storm surge event in the Iberian Peninsula, placing special focus on the nonlinear phenomena.

Recent studies also pointed out the influence of sea state in the residual elevation measured during a storm surge event. Waves can act on sea surface elevation in three different ways: 1) by changing wind-induced stress. This stress depends on the roughness of water surface, which is determined by waves. Classical wind stress parameterisations do not include an explicit dependence on wave field, being implicitly tuned for a wave field that is fully developed. However, if the growth of waves is limited by fetch, time or depth, a nonexplicit description of the dependence of stress with waves can no longer be correct. In recent years different parameterisations that explicitly compute stress as a function of wind and waves [14, 17] have been developed; 2) through the spatial gradients of the radiation stress (radiation stress represents the contribution of wave motions to mean flux of horizontal momentum). The spatial derivatives of this variable should be introduced as forcing terms in the equations of an ocean model in case they are large enough compared with other forcing terms [18]; and 3) by an increase of the bottom friction due to the short period water column orbital velocities induced by waves [9].

We present here a coupled run of the wave spectral model WAM cycle 4 [27] and the HAMSOM model in order to investigate the importance of the first two terms. The influence of the waves in increasing bottom friction only occurs in shallow waters, near coastal regions which, in the present region, can only be resolved with a grid finer than that employed in the simulations.

\section{MATERIALS AND METHODS}

\subsection{The tidal gauge network REDMAR}

The REDMAR network $[2,19]$ consists of 13 acoustic tidal gauges located at Bilbao, Santander, Gijón, La Coruña, Vigo, Tenerife, Las Palmas, Huelva. Sevilla (sluice), Bonanza, Málaga, Valencia and Barcelona.

The tidal gauges were developed by SONAR Ltd. and consist of an ultrasonic transmitter-receiver, located at a certain height over the water surface. The distance to the sea surface is calculated by measuring the speed of the 
sound and the time elapsed between transmission and reception of an acoustic pulse which is sent towards the sea surface and reflected back to the measuring device.

Amplitude and phase values of the harmonic constituents are obtained by using the Foreman analysis and prediction programmes [10].

\subsection{The HAMSOM model}

The HAMSOM $[3,4,22]$, developed by the Institut furr Meereskunde and by Clima Marítimo, is a 3D multi-level ( $\mathrm{z}$ coordinate) finite difference model (Arakawa $\mathrm{C}$ grid) based on the set of Reynolds equations:

$u_{t}+u u_{x}+v u_{y}+w u_{z}+P_{x} / \rho=f v+\partial_{x}\left(A_{h} u_{x}\right)$

$+\partial_{y}\left(A_{h} u_{y}\right)+\left(\Gamma_{x}\right)_{z}$

$v_{t}+u v_{x}+v v_{y}+w v_{z}+P_{y} / \rho=-f u+\partial_{x}\left(A_{h} v_{x}\right)$

$+\partial_{y}\left(A_{h} v_{y}\right)+\left(I_{y}\right)_{z}$

where $u, v$ and $w$ are the vector velocity components, $t$ is time, $P$ is pressure, $\rho$ is water density, $f$ is Coriolis frequency, $\Gamma_{x}$ and $\Gamma_{y}$ are the components of the stress vector and $A_{h}$ is the horizontal eddy viscosity (which in these simulations is kept constant and equal to $200 \mathrm{~m}^{2} \cdot \mathrm{s}^{-1}$ ). Astronomical forcing is neglected. Some authors handle the self-attraction and loading of the ocean tide by a simple scalar multiplier of the elevations in the momentum equations [1]. This is only a crude approximation, and it is particularly poor in ncar-coastal areas [11]. We have therefore chosen to ignore this relatively small forcing term. The formulation is completed with the continuity and hydrostatic equations

$u_{x}+v_{y}+w_{z}=0$

$P_{z}=-\rho g$

where $g$ is the gravitational acceleration.

The model solves the particular expressions arising from the vertical integration of the equations for each level. For the first one, the variation of sea surface elevation should be taken into account in the continuity equation. Since the vertically integrated velocity (the transport) is computed as the product of velocity $x$ total level thickness, which includes sea surface elevation, the continuity equation becomes nonlinear for the first level. Surface stress can be computed as a function of the wind. Different parameterisations like the Charnock relation can be employed. This parameterisation will be replaced by a more sophisticated one that takes into account the effect of the waves. Bottom stress is parameterised by a quadratic law:

$\Gamma_{b}=C_{b} \mathbf{u}_{L}\left|\mathbf{u}_{b}\right|$

where $\mathbf{u}_{h}$ is the horizontal vector velocity at the bottom level of the model and $\mathbf{u}_{L}$ is the vertically averaged horizontal velocity in a friction layer close to the bottom. $C_{b}$ is the dimensionless drag coefficient. A classical value of 0.0025 was selected for all the runs. Bottom friction is treated in a semi-implicit way, $\mathbf{u}_{b}$ being computed in the future time and $\mathbf{u}_{L}$ in the present. An additional sophistication is introduced when computing this last transport: it is calculated in a layer with a constant thickness $(30 \mathrm{~m})$ independently of the vertical discretisation present at the grid point. This helps to avoid large jumps in the values of friction in areas where the bottom level of the model is very thin [22].

The nonlinear terms mentioned here are the horizontal advection of momentum $\left(u u_{x}+v u_{y}\right.$, in the $x$ momentum equation), the bottom stress $\left(\Gamma_{b}\right)$ and the continuity equation for the first layer. The semi-implicit numerical scheme used allows the use of large time steps, in this case $20 \mathrm{~min}$. The model domain covers an area extending from $20^{\circ} \mathrm{N}$ to $48^{\circ} \mathrm{N}$ in latitude and from $34^{\circ} \mathrm{W} \omega 0^{\circ}$ in longitude. Resolution is variable, with an inner high resolution $\left(15^{\prime} \times 10^{\prime}\right)$ domain spanning from $20^{\circ} \mathrm{N}$ to $48^{\circ} \mathrm{N}$ and $20^{\circ} \mathrm{W}$ to $0^{\circ}$. All the plots presented correspond to this region. Figure 1 shows the employed bathymetry. Nine layers are used in the vertical, the first three being $10 \mathrm{~m}$ thick and the remaining increasing in thickness towards the bottom.

\subsection{Tidal modelling}

The study covers both diurnal $(\mathrm{O} 1, \mathrm{~K} 1$ and $\mathrm{P} 1)$ and semidiurnal (M2, S2, N2 and K2) constituents. The model was forced at the open boundaries by imposing the values of amplitude and phase interpolated from the onedegree resolution Richard Ray's tidal planetary model [21]. This model is the result of a response-type tidal analysis of 64 repeat cycles of TOPEX-POSEIDON data.

\subsection{Storm surge modelling}

To explore surge dynamics in the region a typical storm surge event was selected for simulation: 9 February 1995. 
The meteorological situation presents a cold front crossing the Iberian Peninsula, associated with a cut-off low moving zonally to the east at a latitude of $50^{\circ}$ (figure 2). Two other minor fronts, crossing the area on days 11 and 13 , were also included in the simulation period. The model was forced by atmospheric pressure and winds from ECMWF (European Centre for Medium Weather Forecast).

To take into account the nonlinear interactions between tidal and meteorological forcing, residuals were computed in the following way: first, a complete simulation, including tidal and atmospheric forcing, was performed; after that, a tidal simulation (with the seven constituents mentioned carlier, which contain most of the total tidal energy) was carried out for the days of the storm. Residuals were obtained by subtracting sea surface elevations from both simulations.

To investigate the effect of sea state on residuals a coupled run with the WAM wave model was performed.

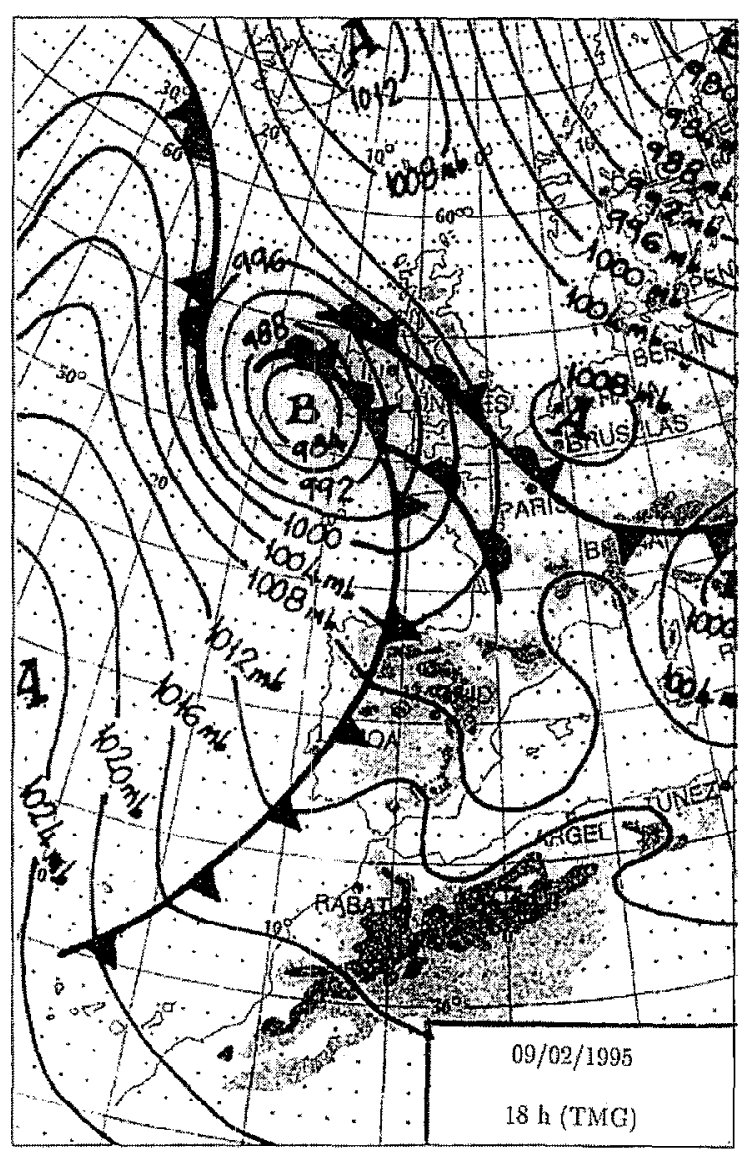

Figure 2. INM (Instituto Nacional de Meteorología) daily bulletin sea level pressure chart at the time of maximal surge.

\subsection{The WAM model}

The WAM model [27] solves the energy balance equation for waves:

$F_{t}(f, \theta)+\nabla \cdot\left(\mathbf{c}_{g} F(f, \theta)\right)=S_{\text {in }}+S_{\text {dis }}+S_{\text {bot }}+S_{\text {nl }}$

where $F(f, \theta)$ is the wave spectrum (in $\mathrm{m}^{2} \cdot \mathrm{s}$ ), $f$ and $\theta$ are the wave component frequency and direction and $\mathbf{c}_{g}$ is the group velocity (the velocity of the wave energy propagation). On the right-hand side of the equation, four source functions represent the wind input, the dissipation due to whitecapping, the bottom dissipation and the nonlinear wave-wave interactions, respectively. The wind input source term is computed as a function of the friction velocity $\left(\mathbf{U}_{*}\right)$, which is an alternative measure for stress defined as:

$U_{*}=\sqrt{\frac{\Gamma_{w}}{\rho_{a}}}$

where $\rho_{a}$ is the air density and $\Gamma_{w}$ the vertical flux of horizontal momentum or wind stress. The cycle 4 version of WAM computes the friction velocity as a function of wind speed and sea surface roughness [14]. This value of friction velocity or its equivalent, wind stress, is used by HAMSOM in the coupled run.

The model was run in an area covering the whole North Atlantic. A two-way nesting technique developed at Clima Marítimo was applied in order to obtain better resolution around the Spanish coast [13]. Time step was $20 \mathrm{~min}$, the same as that employed in the ocean model.

\subsection{Coupling of a wave and an ocean model}

$\Lambda$ s previously mentioned, the spatial derivatives of radiation stress should be introduced as forcing terms in the equations of an ocean model in case they are large enough compared with other forcing terms. Therefore, as a first step, the magnitude of these spatial gradients was evaluated and compared with wind stress. Radiation stress was derived from wave spectrum as computed by WAMl. For deep water [5]:

$S_{i j}=\frac{1}{2} \rho g \int_{0}^{2 \pi} \int_{0}^{\infty} \frac{k_{i} k_{j}}{|\mathbb{K}|^{2}} F(f, \theta) d f d \theta$ 
where $S_{i j}(i, j=x, y)$ is the radiation stress and $k_{i}, k_{j}$ are the components of wave number $\mathbf{K}$.

A deep water law for computing radiation stress was employed (which is a simplification of the complete formula that can be applied to shallow water areas) hecanse our simulation domain is almost entirely dominated by deep waters and because we were only interested in comparing the magnitude of the spatial gradient of the radiation stress with the magnitude of the wind stress.

Figure 3 shows a comparison of the spatial gradient of radiation stress and the wind-induced stress computed at a grid point located at deep water in the Bay of Biscay. As wind stress is one order of magnitude larger than the spatial gradient of radiation stress (since this last forcing is smaller than the variation produced in wind stress by changing the applied parameterisation), we neglect this later forcing in our surge simulations.

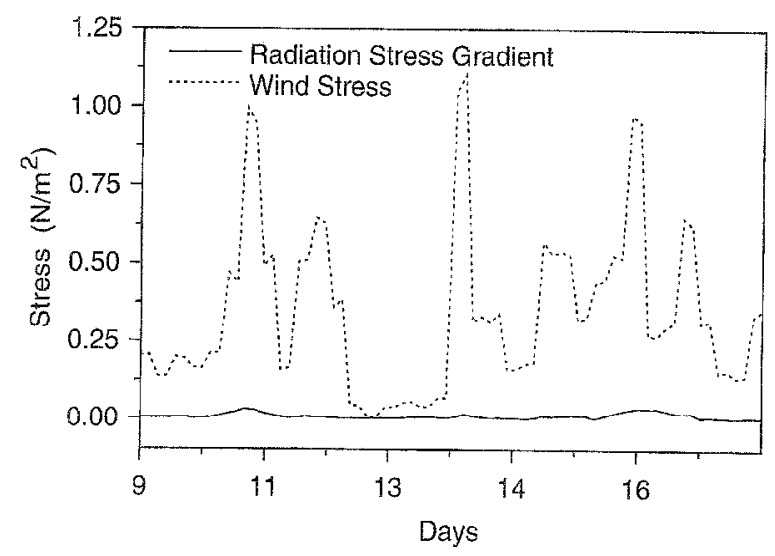

Figure 3. Comparison between wind induced stress and the spatial gradient of radiation stress at a deep point located in the Bay of Biscay.

Although this shows that the radiation stress forcing term can be neglected in this simulation domain, which is dominated by deep water depths, it is well known that it is important for very small-scale simulations, when depthinduced changes in waves, such as shoaling or breaking, are predominant over propagation and generation. An intermediate situation could be present in seas with a wide shelf, like the North Sea, where the inclusion of radiation stress in surge simulation produces some impact (up to $15 \mathrm{~cm}$ in a surge of $2.5 \mathrm{~m}$ ), but it is hard to say if it really improves the performance of the storm surge model [18].

To assess the possible benefits of using an explicitly sea state dependent wind stress, we performed two reference runs with classical parameterisations. For the first one, surface stress was computed as a function of the wind velocity at $10 \mathrm{~m}\left(\mathbf{U}_{10}\right)$, supplied by the ECMWF meteorological model:

$\Gamma_{w}=\rho_{a} C_{D}\left|\mathbf{U}_{10}\right| \mathbf{U}_{10}$

where $\rho_{a}$ is the air density and the drag coefficient $\left(C_{D}\right)$ is parameterised using the Smith and Banke relation [24]:

$C_{D}=\left(0.066\left|\mathbf{U}_{10}\right|+0.63\right) \times 10^{-3}$

Although it is well known that this formulation tends to underestimate stresses and, therefore, surges, we employed this run to compare the stresses obtained by this classical and extended method with those obtained in the coupled run.

A second reference run, which employs the Charnock parameterisation, was used to determine if the good results obtained hy the coupled model could be reproduced with a simple classical parameterisation. We selected Charnock because results can be easily tuned through the value of the constant $\alpha$.

The so-called Charnock reference run and Janssen's theory used in the coupling are based on the fact that friction dominates the dynamic balance of the atmosphere in the bottom boundary layer (roughly, the lowest $10 \mathrm{~m}$ ). This makes the total downward momentum flux near the surface independent of height:

$\frac{d \Gamma_{w}}{d z}=0$

This constant downward momentum transfer is dominated by turbulent wind speed fluctuations but, near the water surface, wave-induced fluctuations of the wind speed can be found, and $\Gamma_{w}$ can be written as the sum of the two contributions:

$\Gamma_{w}=\Gamma_{t}+\Gamma_{w a}$

with the sum being constant. Charnock's and Janssen's theories only differ in their assumptions for the waveinduced stress $\left(\Gamma_{w a}\right)$. In both theories, the turbulent downward momentum transfer $\left(\Gamma_{t}\right)$ can be expressed in terms of the vertical gradient of the mean flow through an 'eddy viscosity' term, dependent on $l$, the so called 'mixing length':

$\Gamma_{t}=\rho_{a}{ }^{2}\left(\frac{\partial U}{\partial z}\right)^{2}$ 
This length is usually taken near the surface as the product of the Karman constant $k$, and the height $z$.

In the Chamock reference run we do not consider an explicit dependence on waves $\left(\Gamma_{w}=\Gamma_{t}\right)$. In this case it is straightforward to integrate the above expressions reaching to the well known logarithmic profile for the wind speed:

$\mathbf{U}(z)=\frac{U_{*}}{k} \ln \left(\frac{z}{z_{0}}\right)$

with the remaining problem being the determination of the integration constant $z_{0}$, called the roughness length. Charnock [8] introduced the following expression, which is dependent on the dimensionless Charnock constant $\alpha$ :

$z_{0}=\frac{\alpha U_{*}^{2}}{g}$

For a given $\alpha$, the Charnock reference run computes $U_{*}$ by means of this relation and the logarithmic wind profile expression at $10 \mathrm{~m}$ height, where the input winds are defined. The constant $\alpha$ represents a mean value of the sea surface roughness and, consequently, a mean value of the sea state. A widle range of values has been proposed for $\alpha$, ranging from 0.01 , which corresponds to a fully developed sea [12] to 0.032 [18], corresponding to a time or fetch limited case.

In Janssen's theory, employed in the coupled run, the wind stress depends on the fraction of the stress carried by the waves [14]. This approach considers the roughness dependent on the sea state by introducing the following wind profile:

$U(z)=\frac{U_{*}}{k} \ln \left(\frac{z+z_{e}-z_{0}}{z_{e}}\right)$

where $z_{e}$, the 'effective roughness', is a parameter depen dent on the sea state through $\Gamma_{w a}$. In the region where $\Gamma_{w a}$ wave tends to zero, $z_{e}$ tends to $z_{0}$ and we have then the classical logarithmic profile now dependent on $z_{e}$. By computing the amount of momentum going into the waves, which depends on $U_{\text {* }}$ and on the wave spectrum, $\Gamma_{w a}$ can be determined and in consequence, $z_{e}$ can be computed. The model behaves as a classical Charnock parameterisation when $\Gamma_{w h} / \Gamma_{w}$ tends to zero, but for young wind seas the drag can be twice as large as it is for old ones. To calculate the surface turbulent stress, there is still the need to consider a 'background' roughness parameter, $z_{0}$, to ensure the good behaviour of the model for developed seas where the $\Gamma_{w a}$ wave tends to zero.
The values of $U_{*}$, computed by WAM every $6 \mathrm{~h}$ following Janssen's theory, are used as wind forcing in the coupled run by means of an interpolation to the HAMSOM grid both in time and space.

\section{RESULTS}

\subsection{Tidal simulations}

Figure 4 shows the amplitude and phase values of M2 obtained by the numerical simulation (for briefness, we will focus on the results for $\mathrm{M} 2$, but similar data were derived for the other harmonics). This figure shows the well known Kelvin wave behaviour of M2, with phases propagating from South to North and amplitudes increasing towards the coast. The French shelf in the Bay of Biscay presents the largest amplitudes and, as far as barotropic dynamics is concerned, is the most complex area in the simulation domain. In this region tidal dynamics can be explained as the result of the combination of a Kelvin propagating wave and a reflected Poincare wave [15].

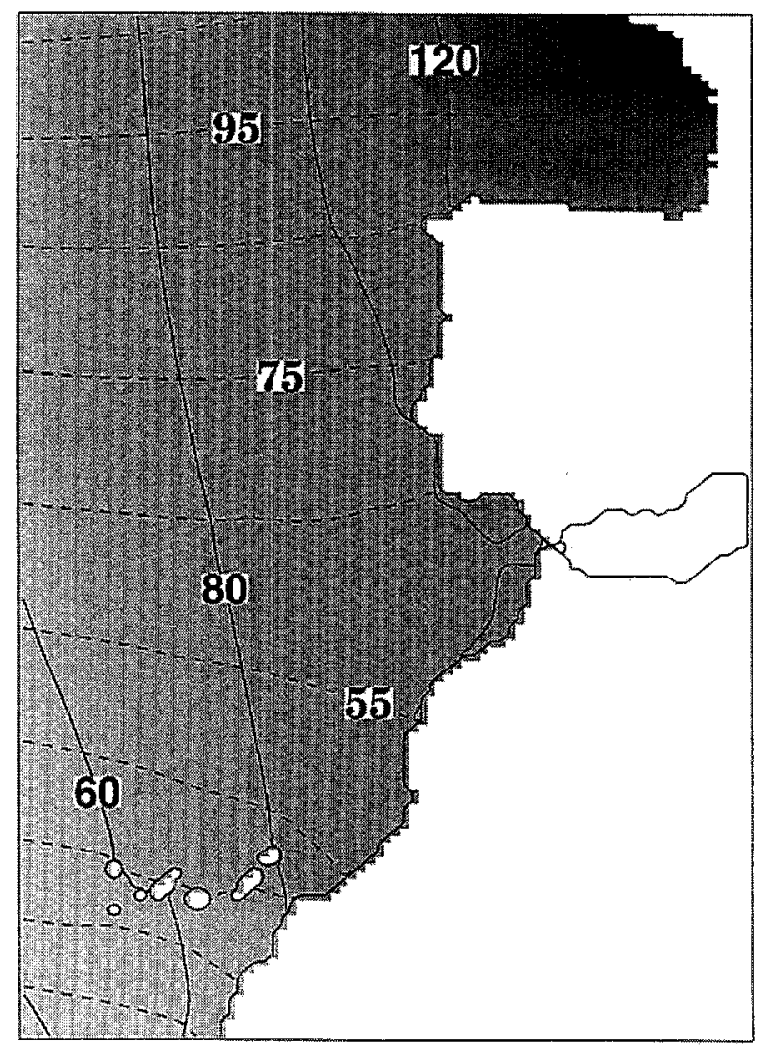

Figure 4. Amplitude in $\mathrm{cm}$ (solid lines) and phase in degrees (dotted lines) of M2. 
Results for semidiurnal components show good agreement with the values derived from applying harmonic analysis routines to the REDMAR measurements [2]; differences in amplitude for $\mathrm{M} 2$ are no larger than $5 \%$ in the Spanish harbours, including those of the Canary Islands (figure 5). Exceptions to this are Bonanza (8.5\%), influ-
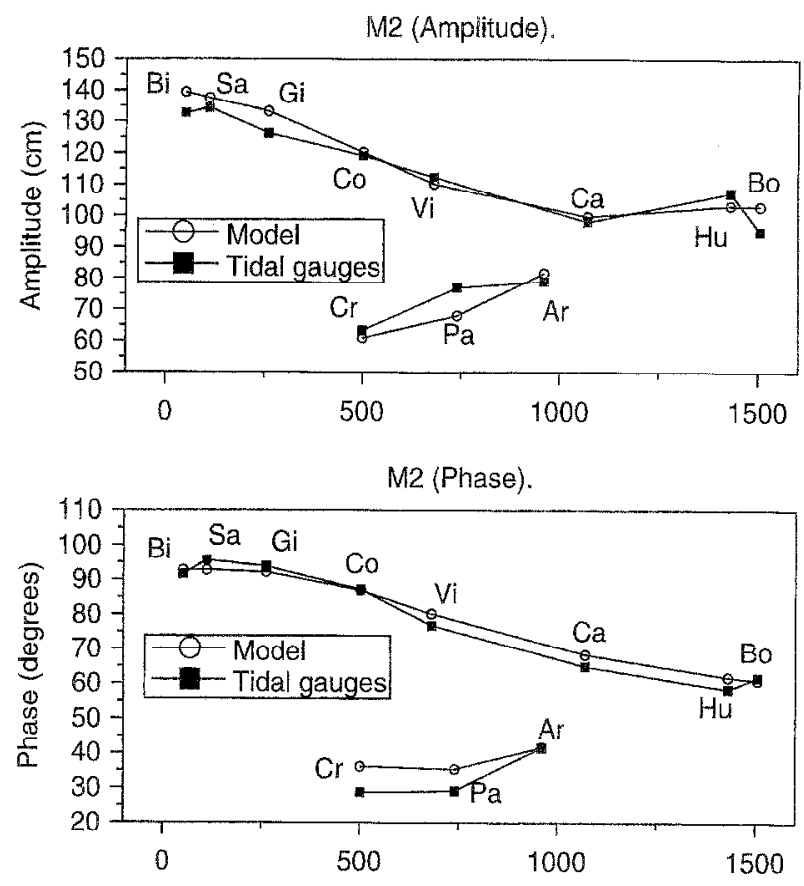

Figure 5. Comparison between amplitudes (upper plot) and phases (lower plot) on the Spanish harbours as obtained by model results and by harmonic analysis of the data provided by REDMAR. Cascais (Ca) and Arrecife (Ar) are included for completeness. Relative geographical distance in $\mathrm{km}$ between stations is estimated in the horizontal axis. The three stations plotted in a different line correspond to the Canary Islands. Bi: Bilbao; Sa: Santander; Gi: Gijón; Co: La Coruña; Vi: Vigo; Hu: Huelva; Bo: Bonanza; Pa: La Palmas; Cr: Santa Cruz de Tenerife.

enced by the Guadalquivir River freshwater outflow, and Las Palmas $(11.4 \%)$. Results of similar accuracy around the Iberian Peninsula were found in previous works [26]. In the French coast, the model produces, in general, values larger than the measured ones (about a $10 \%$ difference). Other numerical models implemented in the French shelf show a general tendency to produce the same kind of overestimation [15]. The agreement with pelagic gauges is excellent, with differences less than $2 \%$ in most of the cases.

The phase is also well reproduced with lags smaller than $7 \mathrm{~min}$ between observed and computed high tide in the
Spanish harbours. Other semidiurnal components show similar behaviour.

The largest values of currents can be found in the French shelf. Figure 6 shows, for the first level of the model, the dramatic change induced by bathymetry in the M2 generated tidal ellipses of this region. Two vectors are additionally included in the tidal ellipses representation; the first one gives the maximal current and the second one corresponds to the velocity value at the beginning of the M2 period (this provides information on the phase lag between different points). The ellipses are rotating clockwise.

Figure 7 shows a comparison between computed and measured M2 tidal ellipses obtained during the TRANSEPLAT 83 and CIRESOL 87 cruises [15]. The position of the stations is marked with inverted triangles in figure 1. Model velocities are first interpolated in the vertical and then analysed by a Fourier technique in order to obtain M2 tidal ellipses at the same depth as the measurements. The agreement is excellent both in orientation and magnitude. The model tends to slightly overestimate tidal current amplitude.

Diurnal constituents show, in all regions of the simulation domain, larger differences with measurements than semidiurnal harmonics, especially in phase data. This can be explained by deticiencies in Ray's data set, which was used as a boundary condition in the model. In fact, it was found that the data from Ray's model showed significant differences with available observations. The origin of this problem must be the small absolute values of the diurnal components (Richard Ray, personal communication), making its altimeter-based determination more difficult. Comparison with gauge data and with other solutions previously presented [7] show that the largest discrepancies are present in the phase values, with differences up to $40^{\circ}$ in the French shelf for K1. To improve simulations, Ray's data were modified to reduce the errors before being used as boundary conditions. Even after these corrections, diurnal components showed a poorer agreement with observations than semidiurnal ones. Comparison with data derived from REDMAR stations indicated differences up to $2 \mathrm{~cm}$ and maximal phase lags as large as $1 \mathrm{~h}$. It is also interesting to note that, for diurnal constituents, sometimes large differences can be found in the values measured by gauges of different institutes placed at the same location. For example, amplitude for KI at Vigo is $1.68 \mathrm{~cm}$ following IEO results, while REDMAR data provides a value of $2.49 \mathrm{~cm}$. The small values of these amplitudes compared with those of the main semidiurnal 


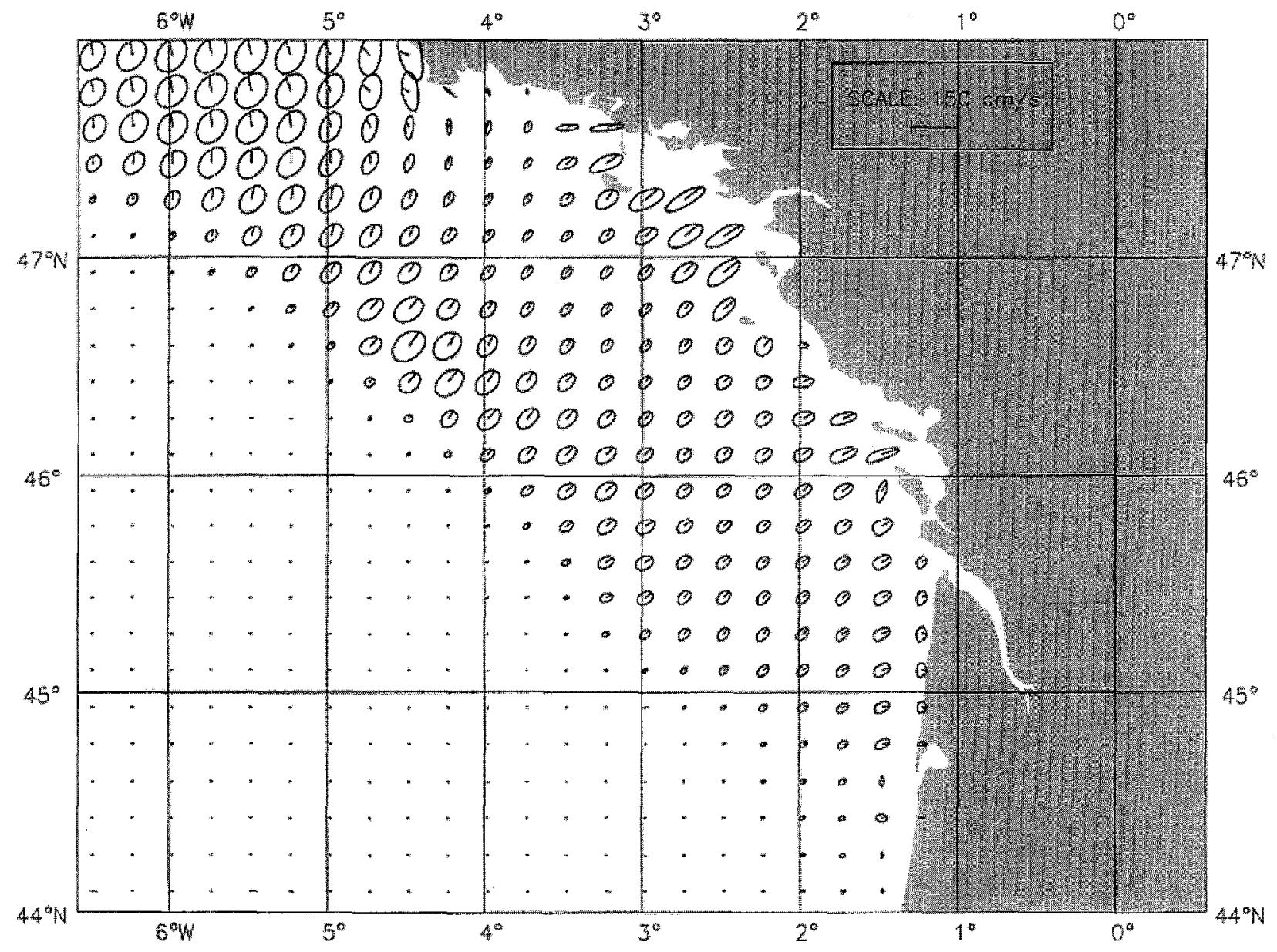

Figure 6. Tidal ellipses for M2 in the Bay of Biscay at first level $(0-10 \mathrm{~m})$.

constituents should be in the origin of the largest relative discrepancies between measurements.

\subsection{Nonlinear traniffer of energy to higher order har- monics}

A Fourier analysis technique was applied to the results of M2 and S2 simulations to calculate, in every grid point, the nonlinear transfer of energy from semidiurnal to higher order harmonics, such as M4 and M6. Those transfers were found to be important in the Hrench continental shelf in the Bay of Biscay (figure 8). Some M4 generation (maximal amplitude of $3 \mathrm{~cm}$ ) was also found at the widest part of the African shelf, south of Cape Bojador.

It is important to note that, in the case of the Bay of Biscay, the results obtained correspond only to the locally generated M4 and M6, and do not take into account the energy contained in these constituents that is generated outside the simulation domain and propagated into the French shelf (the English Channel is an important area of M4 generation). Amplitude of the locally generated M4 was found to be around $14 \mathrm{~cm}$ in some locations of the French coast, in very good agreement with results from Le Cann [15]. Tidal gauge measurements in the area show a total M4 amplitude (which reflects both English Channel and locally generated energy contributions) of $30 \mathrm{~cm}$. Ray's data set does not contain information about shallow water harmonics, so it was not possible to produce an altimeter-derived data set coherent with the M2 available data to employ as a boundary condition for M4 and M6.

To investigate the relative contributions of the different nonlinear terms in M4 generation, three separate runs of M2 were performed, activating on each one only one of 


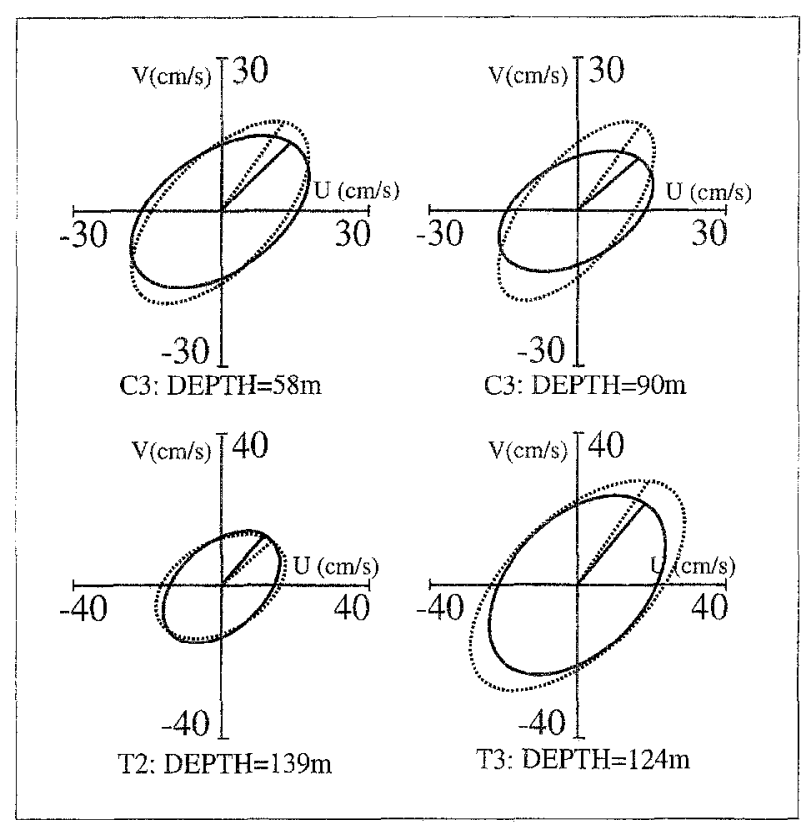

Figure 7. Comparison of measured (solid line) and computed (dotted line) M2 tidal ellipses at stations C3, T2 and T3.

these terms. From these runs it was found that the largest contribution to M4 was induced by bottom friction (roughly $50 \%$ ), followed by the effect of nonlinear continuity equation $(40 \%)$ and the advection of momentum terms $(10 \%)$. These percentages pretend to be only a crude estimate of the relative importance of the terms that contribute to the nonlinear transfers in this particular region and can be modified by changes in the drag coefficient $\left(C_{b}\right)$, which is a tuning variable.

\subsection{Storm surge simulation: results of the coupling}

Results of the coupled model show good agreement with residuals obtained from the REDMAR (figure 9). Comparison with the first reference run, which employs Smith and Banke formulation to compute the drag coefficient, shows that stresses produced by WAM, following Janssen's theory, are larger than those obtained by the classical approach (figure 10). This is an expected result because, although Smith and Banke's parameterisation is widely used, it is well known that it tends to produce wind stress values that are too low, thus underestimating the surges.

$\Lambda$ s previously mentioned, a second reference run, which employs Charnock's parameterisation, was used to determine if the good results obtained by the coupled model could be reproduced with a simple classical parameterisation. We tuned this reference run to fit the results of the coupled model for the largest peak of the storm. The $\alpha$ value of 0.032 proposed by Mastenbroek was found to produce only very small differences, not only in the largest peak mentioned, but also in the rest of the time series. Figure 9 shows the computed residual elevations (using the Charnock relation and the coupled model) compared with those obtained from REDMAR. It is important to note that, although both runs show good

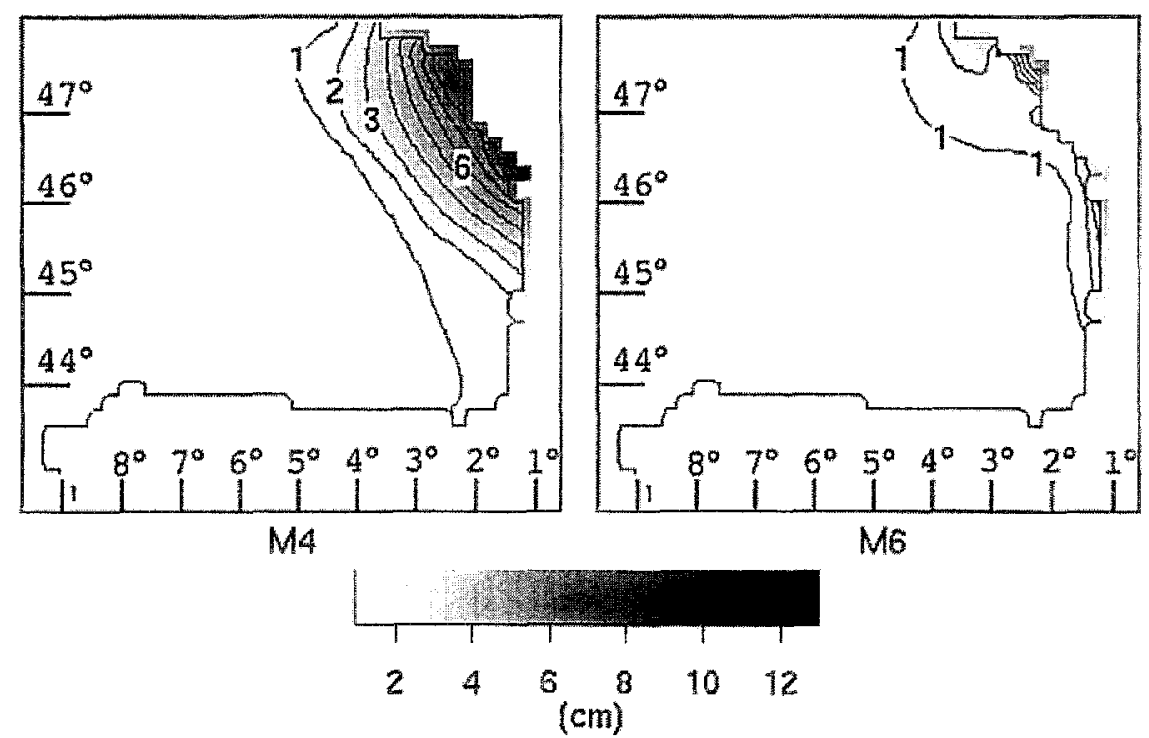

Figure 8. Amplitude of the locally generated M4 (left) and M6 (right) constituents in the French shelf. 

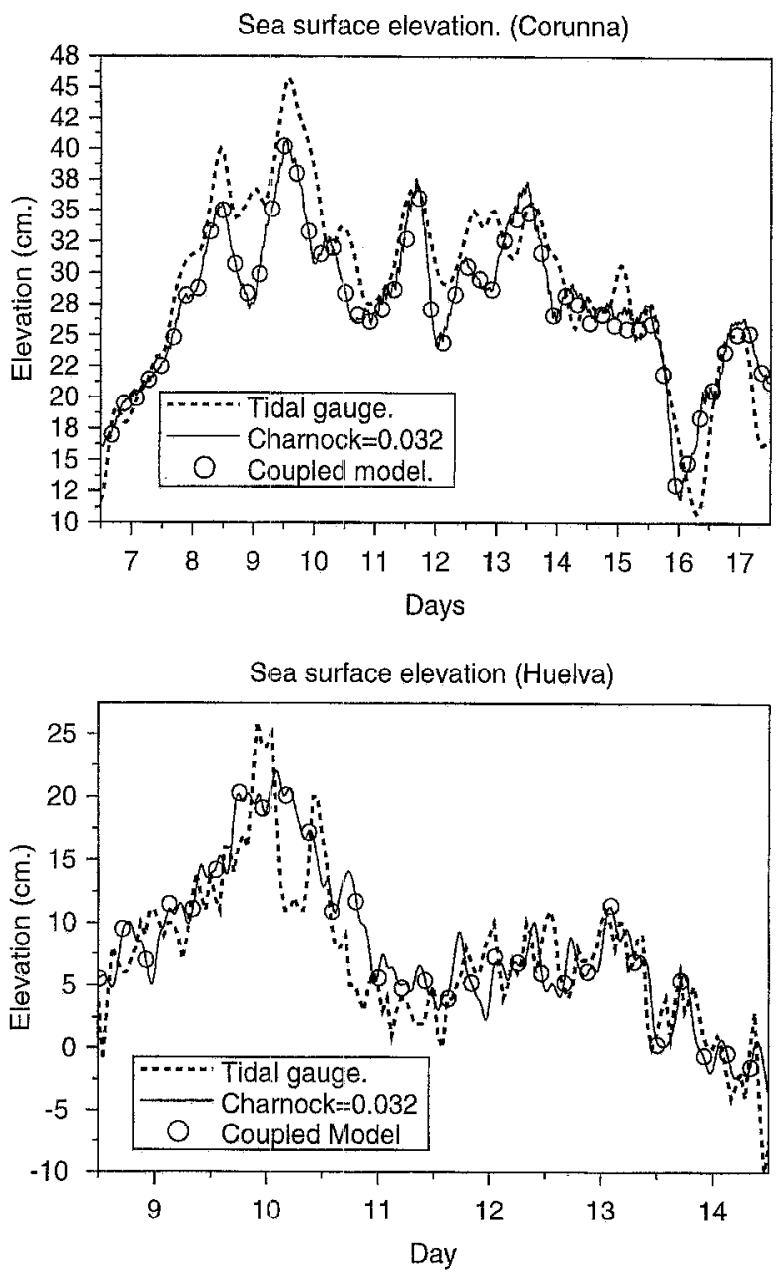

Figure 9. Comparison of residual elevation obtained by REDMAR (dotted line) with those obtained by the coupled model (circles) and by HAMSOM employing the Charnock relation (solid line).

agreement with residuals obtained from RFDMAR, no tuning was needed in the coupled run. During the peaks of the storm, when high wind speeds are present and the sea surface roughness is very high due to the young waves, the wind stresses produced by Janssen's theory (figure 10) tended to be larger than those produced by the Charnock parameterisation. During calmed periods, a sea state corresponding to old wind sea was present and the Charnock formulation produced larger stresses than those found in the coupled run.

When analysing these results we must keep in mind that, as previously mentioned, sea surface evolution during the surge is mainly dominated by atmospheric pressure variations, due to the absence of a wide continental shelf. Additional separate runs for pressure and wind indicate that roughly $70 \%$ of the residual is produced by pressure forc-

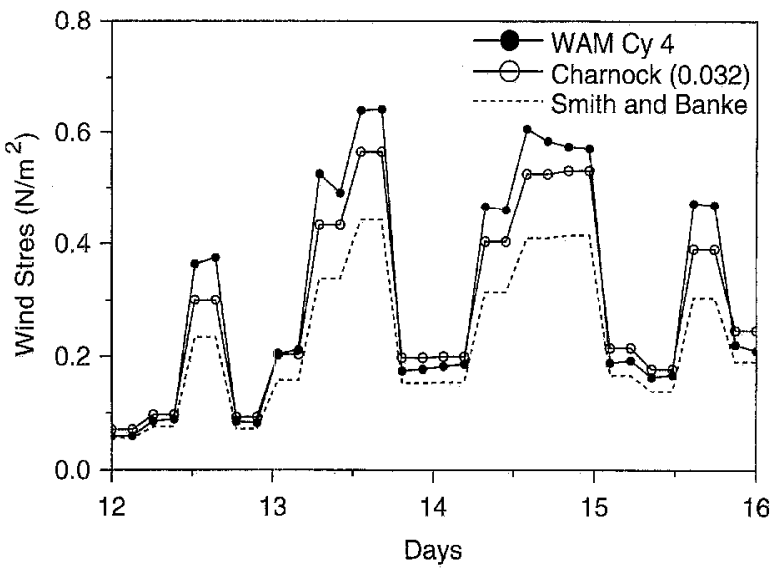

Figure 10. Wind stress during the simulation as computed by Smith and Banke's, Charnock's and Janssen's (WAM Cy 4) theories at a point located inside the model domain $\left(43^{\circ} \mathrm{N}\right.$ and $\left.12^{\circ} \mathrm{W}\right)$.

ing. This implies that, even when changes introduced in the wind stress parameterisations produce significant variations in the wind-induced part of the surge, the impact on the final residual elevation could be relatively small.

\subsection{Nonlinear transfer of energy between tidal and atmospheric forcing}

The nonlinear contribution of tides to sea surface elevation during storm surge events was also investigated. As mentioned earlier, the residuals for the February 1995 storm were computed by subtracting the sea surface elevation from a run that only included tides to those of the simulation that included both forcings, tidal and meteoro-

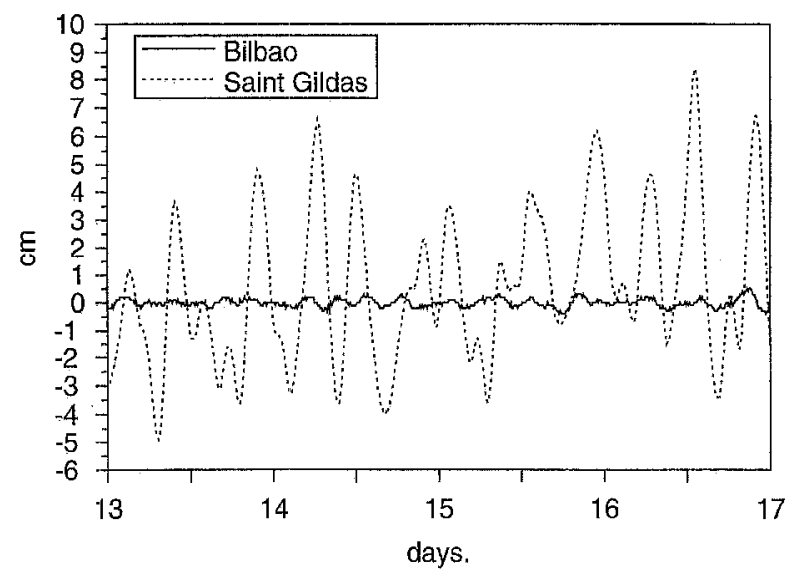

Figure 11. Differences (in cm) at Bilbao and Saint Gildas obtained in the computation of residuals between a simulation that includes both tidal and meteorological forcing and another one that computes residuals only as a function of meteorological forcing. 
logical. Residuals computed in this way include the energy contribution arising from the nonlinear interaction between tidal and meteorological forcing.

To evaluate the magnitude of this nonlinear interaction, we generate, with the coupled model, an additional set of residual elevations. This second data set was obtained by simply forcing the model with atmospheric data, and considering the sea surface elevation as the residual. Differences between both residual data sets show the nonlinear contribution of tides to sea surface elevation in the surge. Those differences (figure 11) were found to be very small in the Spanish Atlantic coast, but important in the French coast (about $10 \mathrm{~cm}$ ). This region coincides with the area where nonlinear phenomena associated with M4 generation were found to be more important.

\section{DISCUSSION AND CONCLUSIONS}

A description of the barotropic dynamics in the eastern North Atlantic was obtained both by numerical simulations and in situ measurements. A good agreement was found between model results and the measurements provided by REDM $\Lambda$ R, making us confident that the validity of the results obtained by the simulations could be extended to other areas where no tidal gauges are present. The tidal currents generated with the model are also in good agreement with the available data.

Nonlinear generation of higher order harmonics were found to be important in the French coast of the Bay of Biscay and less signicant around the Iberian Peninsula. Further studies should be done in order to investigate the effect of increasing the spatial resolution in the numerical simulations. It is possible that some nonlinear effects affecting tidal gauge measurements are unsolved at this resolution. Measurements from some stations (as Santander which is inside an almost closed bay) show oscillations that are unsolved with the classical harmonic analysis and must have their origin in nonlinear phenomena. As the scale of the Santander Bay is unsolved by the current model, we cannot investigate the origin of these oscillations unless we increase the spatial resolution.
Residuals during a storm surge event were correctly simulated by the coupled wave and ocean model fed by ECMWF atmospheric model results. The magnitude of spatial gradient of radiation stress was found to be smaller than the uncertainties induced by the employed parameterisations; thus, this forcing was not included in the coupling.

No tuning was necessary when employing Janssen's theory to reproduce the residuals during the surge, but the good results obtained by the coupled model can be reproduced by tuning the constant $\alpha$ in the Charnock parameterisation. This fact should be further checked with other test cases. If the same value of $\alpha$ is found to produce good results in other storm surges, then we could argue that, from a operational point of view, the coupling is no longer needed and predictions of the evolution of residuals could be done by means of the Charnock parameterisation, which is obviously simpler from a computational point of view.

The characteristics of barotropic dynamics around the Iberian Peninsula were found to be marked by the presence of a very narrow continental shelf, being storm residuals mainly induced by atmospheric pressure variations and having the nonlinear phenomena of a small effect at this resolution. This cannot be applied to the French coast of the Bay of Biscay, where M4 generation and nonlinear interactions between tidal and atmospheric forcing were detected.

It is left to future works to produce longer time runs, covering storms of different characteristics, in order to statistically validate the results of this work.

\section{Acknowledgements}

We are indebted to Isabel Macias, Alan Cantos, Vassilis Zevekis, Jesus Pedreira and Bernard Le Cann for help in the final revision of this work. We also wish to thank José D. López for help with the graphical software. This research has been partially funded by the $\mathrm{EC}$ as part of the MAST ECAWOM project.

\section{REFERENCES}

[1] Accad Y., Pekeris C.L., Solution of the tidal equations for the M2 and $\$ 2$ tides in the world oceans from a knowledge of the tidal potential alone, Philos. Tr. Roy, Soc. A 290 (1978) 235266. 
[2] Alvarez F.E, Rodríguez S.A.I., Pérez G.B., A description of the tides in the Eastern North Atlantic, Progress in Oceanography (accepted for publication).

[3] Backhaus J.O., A semi-implicit scheme for the sallow water equations for application to shelf sea modelling, Cont. Shelf Res. 2 (4) (1983) $243 \% 254$.

[4] Backhaus J.O., A three-dimensional model for simulation of shelf sea dynamics, Dt. Hydrogr. Z. 38 (H.4) (1985) 164-187.

[5] Battjes J.A., Computation of set-up, longshore currents, runup and over-topping due to wind generated waves (dissertation), Commun. Hydraul. (1974) 74-82.

[6] Bowden K.F., Physical Oceanography of Coastal Waters, Ellis Horwood, 1983.

[7] Cartwright D.E., Spencer R., Vassie J.M., Woodworht P.L., The tides of the Atlantic Ocean, $60 \mathrm{~N}$ to $30 \mathrm{~S}$, Philos. Tr. Roy. Soc. A 324 (1988) 513-563.

[8] Charnock H., Wind stress on a water surface, Quartnary J. Roy. Meteor. Soc. 81 (1955) 639-640.

[9] Davies A.M., Lawrence J., Examining the influence of wind and wave turbulence on tidal currents, using a three-dimensional hydrodynamic model including wave-current interaction, J. Phys. Oceanogr. 24 (12) (1994) 2441-2459.

[10] Foreman F.G.G., Manual for Tidal Heights Analysis and Predictions, Institute of Ocean Sciences, Patricia Bay, Victoria, B.C. 1977,97 pp.

[11] Francis O., Mazzega P., Global charts of ocean tide loading effects, J. Geophys. Res. 95 (C7) (1990) 11411-11424.

[12] Garratt J.R., Review of drag coefficients over oceans and continents, Mon. Weather Rev. 105 (1977) 915-929.

[13] Gómez M., Carretero J.C., A variable grid spacing scheme for the WAM model: application to the Spanish coast, Publicación n $^{\cap} 57$ de Clima Marítimo (1994).

[14] Janssen P.A.E.M., Quasi linear theory of wind wave generation applied to wave forecasting, J Phys. Oceanogr. 21 (1991) 1631-1642.

[15] Le Cann B., Barotropic tidal dynamics of the Bay of Biscay Shelf: observations, numerical modelling and physical interpretation, Cont. Shelf Res. 10 (8) (1990) 723-758.
[16] Le Provost C., Bennet A.F., Cartwright D.E., Ocean tide for and from TOPEX/POSEIDON, Science 267 (1995) 639-642.

[17] Makin V.K., Chalikov D.V., Calculating momentum and energy fluxes going into developing waves, Izv. Atmos. Ocean. Phys. 22 (1986) 1015-1019.

[18] Mastenbroek C., Burgers G., Janssen P.A.E.M., The dynamical coupling of a wave model and a storm surge model through the atmospheric boundary layer, J. Phys. Oceanogr. 23 (1993) 1856-1866.

[19] Pérez B., Rodríguez I., REDMAR. Spanish harbours tidal gauges network. Processing of tidal data, Publicación $n^{\circ} 57$ de Clima Marítimo (1994).

[20] Pugh D.I., Tides Surges and Mean Sea Level, Wiley \& Sons, 1987.

[21] Ray R.D., Sánchez B.V., Cartwright D.E., Some extensions to the response method of tidal analysis applied to TOPEX/ POSEIDON (abstract), EOS, Transactions of the American Geophysical Union, 75 (Spring Meeting Suppl. 108) (1994).

[22] Rodríguez I., Alvarez E., Modelo Tridimensional de Corrientes. Condiciones de aplicación a las costas españolas y análisis de resultados para el caso de un esquema de mallas anidadas, Publicación n ${ }^{\circ} 42$ de Clima Marítimo, 1991.

[23] Rodríguez I., Alvarez E, Kröhn J., Backhaus J.O., A mid-scale tidal analysis of waters around the north-western corner of the Iberian Peninsula, in: Computer Modelling in Ocean Engineering 91, Balkema, 1991.

[24] Smith S.D., Bank E.G., Variation of the sea surface drag coefficient with wind speed, Quartnary J. Roy. Meteor. Soc. 101 (1975) 665-673.

[25] Vested H.J., Nielsen J.W., Jensen H.R., Kristensen K.B., Skill Assessment of an Operational Hydrodynamic Forecast System for the North Sea and Danish Belts. Quantitative Skill Assessment for Coastal Ocean Models, AGU, Washington D.C., 1995, pp. 373-398.

[26] Vincent P., Le Provost C., Semidiurnal tides in the Northeast Atlantic from a finite element numerical model, J. Geophys. Res. 93 (C1) (1988) 543-555.

[27] WAMDI group. The WAM model - a third generation ocean wave prediction model, J Phys. Oceanogr. 18 (1988) 1775 1810 . 